\title{
Synthesis and characterization of bis-azo 1,2,4,5-tetrazine dyestuff
}

\author{
Tawfik A. Khattab* and Mohamed Rehan \\ Textile Industries Research Division, National Research Centre, Cairo 12622, Egypt
}

\begin{abstract}
$\mathbf{T}$ HE synthesis and characterization of symmetrical 3,6-Bis(2-(4-(dodecyloxy) phenyl)-1-(4-(phenyl)diazene)-1,2,4,5-tetrazine were reported. Our new symmetrical bis-azo tetrazine was obtained via addition reaction of 4-(2-(4-decyloxyphenyl)diazenyl)benzonitrile with hydrazine hydrate and then subjected to oxidation process. The molecular structure was verified by different analytical techniques including fourier-transform infrared spectroscopy (FT-IR), elemental analysis and nuclear magnetic resonance $\left({ }^{1} \mathrm{H}\right.$ - and $\left.{ }^{13} \mathrm{C}-\mathrm{NMR}\right)$ spectral measurements.
\end{abstract}

As a result of the large range of applications of tetrazine-based products, the inclusion of a heterocyclic tetrazine moiety in molecular structures of different compounds affords such materials new significant properties [1, 2]. Symmetrical tetrazine-based materials are a famous group of aromatic heterocyclics that have been applied in a diversity of research areas, such as anti-tumors, metallosupramolecular self-assembly, insecticides, electrochemical materials, fluorescent products, electroactive materials, bio-orthogonal label and cell sensing [3-9]. Tetrazines can be considered as one of the highest electron deficient aromatic compounds. They are able to introduce high electron-affinity and charge-transfer as conjugated chemical materials. Tetrazines display brilliant shades and their emission properties can be selectively quenched by electron rich compounds [1012]. Tetrazines have been also interested as sensors in the molecular detection of ecological contaminants, as anion binders and in metallic coordination. They are readily able to interact in inverse-demand Diels-Alder. These high nitrogencontaining energetic 1,2,4,5-tetrazines are well known for their application as propellants, explosives and pyrotechnic ingredients [13-16]. In this research study, we depict the synthetic approach of bis-azo symmetrical tetrazine.

As shown in Scheme 1 and according to literature procedures [12, 17-19], the 4-(2-(4-hydroxyphenyl)diazenyl)benzonitrile 1 was prepared starting from 4-cyanoaniline which afforded the diazonium salt followed by azo-coupling with phenol. The compound 4-(2-(4-nonyloxyphenyl)diazenyl)benzonitrile 2 was prepared from a mixture of compound $\mathbf{1}$, anhydrous potassium carbonate, bit of potassium iodide, and 1-bromononane in dry $\mathrm{DMF}$ at $60^{\circ} \mathrm{C}$ to afford an orange powder with a relatively good yield. Our target compound 3,6-bis(2-(4(nonyloxy)phenyl)-1-(4-(phenyl)diazene)-1,2,4,5-tetrazine $\mathbf{3}$ was synthesized from 2 via addition interaction with hydrazine hydrate to give the dihydrotetrazine intermediate, which was then subjected to oxidation employing sodium nitrite to give the bis-azo 1,2,3,4-tetrazine product 3 in a moderate yield.

"Corresponding Author: Tawfik A. Khattab; Email: ta.khattab@nrc.sci.eg

DOI: $10.21608 /$ JTCPS.2018.5033.1003

C2018 National Information and Documentation Centre (NIDOC) 


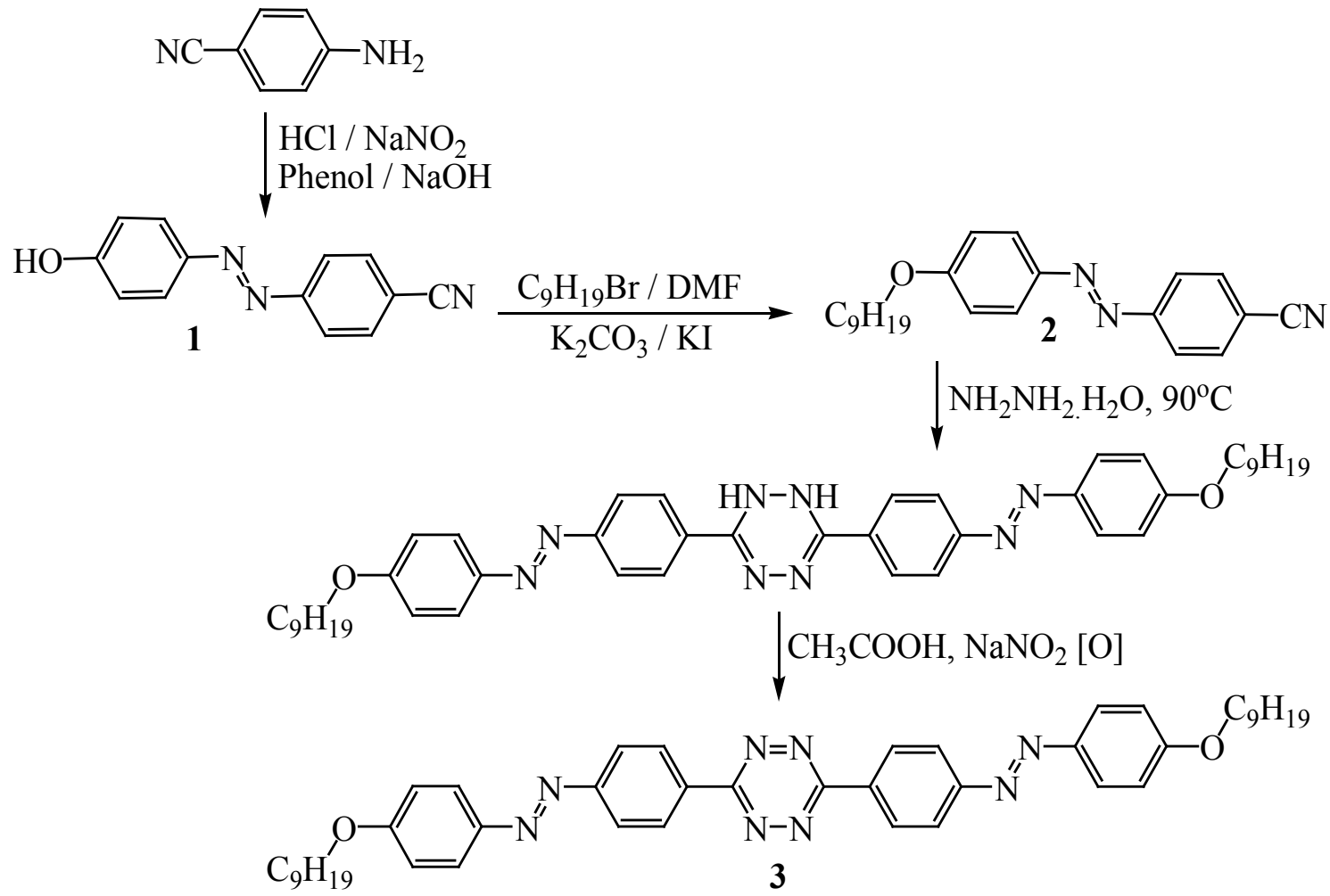

Scheme 1. Synthetic path for new bis-azo sym-tetrazine chromophore 3.

Form the ${ }^{1} \mathrm{H}-\mathrm{NMR}$ spectrum of the tetrazine compound 3 , the three peaks at 8.16, 7.87, 7.13 ppm were attributed to the four phenyl azo moieties, while the ${ }^{13} \mathrm{C}-\mathrm{NMR}$ displayed nine signals in the aromatic area and nine signals for the aliphatic moieties. Our bis-azo symtetrazine dye can be applied as disperse dyestuff for hydrophobic fibers, such as polyester since it can be acknowledged as a non-ionic small-size molecular structure with a very low solubility in water. In conclusion, a new bis-azo sym-tetrazine was effectively prepared and verified according to FT-IR, elemental analysis, and ${ }^{1} \mathrm{H}$ - and ${ }^{13} \mathrm{C}-\mathrm{NMR}$ spectroscopic methods.

\section{Experimental details}

\section{Materials and Methods}

Melting points were measured on Stuart SMP30 and were recorded uncorrected in degree Celsius $\left({ }^{\circ} \mathrm{C}\right)$. Fourier-transform infrared (FT-IR) spectra were determined by a JASCO FT/IR4700 spectrophotometer with a spectral resolution of $4 \mathrm{~cm}^{-1}$ and in the wavenumber range of 400 $4000 \mathrm{~cm}^{-1}$. Elemental analyses $(\mathrm{C}, \mathrm{H}, \mathrm{N})$ was made using PerkinElmer 2400 analyzer (PerkinElmer, Norwalk, CT, United States). NMR spectra were reported by a BRUKER AVANCE 400 spectrometer at $400 \mathrm{MHz}$; chemical shifts were recorded in $\mathrm{ppm}$ relative to tetramethylsilane internal standard.

Solvents employed in this research study were obtained from Fluka and Aldrich for both of the preparation processes and spectroscopic measurements (spectroscopic grade). Compounds $\mathbf{1}$ and $\mathbf{2}$ were synthesized according to literature procedure $[17,18]$ starting from 4-cyanoaniline which is a commercial material from SigmaAldrich. All reactions were followed by thin layer chromatography (TLC) employing Merck aluminum plates pre-coated with silica gel PF254; $20 \times 20 \mathrm{~cm}, 0.25 \mathrm{~mm}$, and monitored visually under UV lamp (254 or $365 \mathrm{~nm})$.

Synthetic approaches:

Synthesis of 4-(2-(4-hydroxyphenyl)diazenyl) benzonitrile (1)

Prepared from 4-cyanoaniline (10 mmol) was dissolved in $\mathrm{HCl}(37 \% ; 15 \mathrm{~mL})$, cooled to $0-5^{\circ} \mathrm{C}$ in an ice-bath with stirring and subjected to diazotization by slow addition of a solution of sodium nitrite $(10 \mathrm{mmol})$ in distilled water 
(5 mL). Phenol (10 mmol) was then dissolved in $10 \mathrm{wt} \%$ of $\mathrm{NaOH}$ solution $(10 \mathrm{~mL})$ and cooled to $0-5^{\circ} \mathrm{C}$ and the cold diazonium salt solution was added dropwise. The mixture was acidified using aqueous $\mathrm{HCl}$ to afford an orange precipitate which was filtered off, washed with distilled water, air dried and recrystallized from ethanol to get an orange powder (yield $76 \%$ ). m.p. $>300^{\circ} \mathrm{C}$. ${ }^{1} \mathrm{H}-\mathrm{NMR}$ (400 MHz, DMSO-d $)$ ppm: $\delta 10.57$ (s, $1 \mathrm{H}, \mathrm{ArOH}), 8.03$ (d, 2H), 7.92 (d, 2H), 7.85 (d, $2 \mathrm{H}), 6.96(\mathrm{~d}, 2 \mathrm{H})$.

Synthesis of 4-(2-(4-nonyloxyphenyl)diazenyl) benzonitrile (2)

A mixture of 4-(4'-hydroxyphenylazo) benzonitrile (10 $\mathrm{mmol})$, anhydrous potassium carbonate $(20 \mathrm{mmol})$, bit of potassium iodidie, and 1-bromononane $(10 \mathrm{mmol})$ was stirred under nitrogen in dry DMF $(15 \mathrm{~mL})$ at $60^{\circ} \mathrm{C}$ for 8 hours. The mixture was then added to cold distilled water to afford solid precipitate which was isolated by filtration and washed with distilled water then hexane. An orange powder was obtained (yield 76\%). m.p. $106-108^{\circ} \mathrm{C} .{ }^{1} \mathrm{H}-\mathrm{NMR}(400 \mathrm{MHz}$, $\left.\mathrm{CDCl}_{3}\right)$ ppm: $\delta 7.96(\mathrm{dd}, 4 \mathrm{H}), 7.81(\mathrm{~d}, 2 \mathrm{H}), 7.04$ $(\mathrm{d}, 2 \mathrm{H}), 4.05(\mathrm{t}, 2 \mathrm{H}), 1.81(\mathrm{q}, 2 \mathrm{H}), 1.47(\mathrm{~m}, 2 \mathrm{H})$, $1.32(\mathrm{~m}, 8 \mathrm{H}), 1.28(\mathrm{t}, 2 \mathrm{H}), 0.92(\mathrm{t}, 3 \mathrm{H})$.

Synthesis of 3,6-Bis(2-(4-(nonyloxy)phenyl)-1-(4(phenyl)diazene)-1,2,4,5-tetrazine (3)

A mixture of compound $2(10 \mathrm{mmol})$ and excess of hydrazine hydrate $(8 \mathrm{~mL})$ was heated at $90^{\circ} \mathrm{C}$ in an oil bath for 9 hours. After cooling to ambient temperature, the produced precipitate was filtered off, washed with hexane and recrystallized from ethanol to give a red solid (yield 56\%). The produced compound ( $5 \mathrm{mmol}$ ) was stirred in glacial $\mathrm{CH}_{3} \mathrm{COOH}(10 \mathrm{~mL})$ and then a $10 \mathrm{~mL}$ solution of $\mathrm{NaNO}_{2}$ (5 equiv.) was added slowly over 8 minutes with stirring. The mixture was stirred for an extra 20 minutes; the residual was isolated by filtration, washed with hexane, and finally air-dried to give a red powder (yield 68\%). m.p. $>300^{\circ} \mathrm{C}$. ${ }^{1} \mathrm{H}$ NMR $(400 \mathrm{MHz}$, DMSO-d $)$ ppm: $\delta 8.16(\mathrm{~d}, 4 \mathrm{H}), 7.87(\mathrm{dd}, 8 \mathrm{H})$, $7.13(\mathrm{~d}, 4 \mathrm{H}), 4.07$ (t, 4H), $1.78(\mathrm{q}, 4 \mathrm{H}), 1.43(\mathrm{~m}$, 4H), $1.26(\mathrm{~m}, 20 \mathrm{H}), 0.87(\mathrm{t}, 6 \mathrm{H}) .{ }^{13} \mathrm{C}$ NMR (400 MHz, DMSO-d $)$ ppm: $\delta 161.79,160.38,151.24$, $146.60,135.48,126.76,124.86,123.09,115.47$, $68.42,31.73,29.52,29.41,29.21,29.08,25.93$, $22.62,14.48$

Acknowledgements: Authors are gratefully thankful for the technical support from National Research Centre, Cairo, Egypt.

\section{$\underline{\text { References }}$}

1. Neal K. Devaraj, Ralph Weissleder, and Scott A. Hilderbrand. "Tetrazine-based cycloadditions: application to pretargeted live cell imaging." Bioconjugate chemistry 19, no. 12 (2008): $2297-$ 2299.

2. Neal K. Devaraj, and Ralph Weissleder. "Biomedical applications of tetrazine cycloadditions." Accounts of chemical research 44, no. 9 (2011): 816-827.

3. V. P. Krivopalov, M. B. Bushuev, Yu V. Gatilov, and O. P. Shkurko. "Synthesis of symmetrical di (pyrimidin-2-yl)-1, 2, 4-triazoles and di (pyrimidin-2-yl)-1, 2, 4, 5-tetrazines." Russian Chemical Bulletin 59, no. 9 (2010): 1808-1816.

4. Gilles Clavier, and Pierre Audebert. "s-Tetrazines as building blocks for new functional molecules and molecular materials." Chemical reviews 110 , no. 6 (2010): 3299-3314.

5. Yong-Hua Gong, Fabien Miomandre, Rachel Méallet-Renault, Sophie Badré, Laurent Galmiche, Jie Tang, Pierre Audebert, and Gilles Clavier. "Synthesis and Physical Chemistry of s-Tetrazines: Which Ones are Fluorescent and Why?." European Journal of Organic Chemistry 2009, no. 35 (2009): 6121-6128.

6. R. G. Dickinson, and N. W. Jacobsen. "A new sensitive and specific test for the detection of aldehydes: formation of 6-mercapto-3-substituteds-triazolo [4, 3-b]-s-tetrazines." Journal of the Chemical Society D: Chemical Communications 24 (1970): 1719-1720.

7. Patrick Roffey, and John P. Verge. "Some reactions of 3, 6-disubstituted-s-tetrazines; A new synthesis of the 1, 2, 4-triazine ring system." Journal of Heterocyclic Chemistry 6, no. 4 (1969): 497-502.

8. Yingjie Zhao, Yongjun Li, Zhihong Qin, Runsheng Jiang, Huibiao Liu, and Yuliang Li. "Selective and colorimetric fluoride anion chemosensor based on s-tetrazines." Dalton Transactions 41, no. 43 (2012): 13338-13342.

9. S. A. Lang Jr, B. D. Johnson, E. Cohen, A. E. Sloboda, and E. Greenblatt. "Aryl-s-tetrazines with antiinflammatory activity." Journal of medicinal chemistry 19, no. 12 (1976): 14041409. 
10. H. H. Takimoto, and G. C. Denault. "3-Aminos-tetrazines from the thermal decomposition of 4-amino-3-azido-s-triazoles." Tetrahedron Letters 7, no. 44 (1966): 5369-5373.

11. Waluk, Jacek, Jens Spanget-Larsen, and Erik W. Thulstrup. "Electronic states of symmetrically disubstituted s-tetrazines." Chemical physics 200, no. 1-2 (1995): 201-213.

12. Tawfik A. Khattab, "Synthesis and Selfassembly of Novel s-Tetrazine-based Gelator." Helvetica Chimica Acta 101, no. 4 (2018): e1800009.

13. Melissa L. Blackman, Maksim Royzen, and Joseph M. Fox. "Tetrazine ligation: fast bioconjugation based on inverse-electrondemand Diels- Alder reactivity." Journal of the American Chemical Society 130, no. 41 (2008): 13518-13519.

14. Dale L. Boger, and Scott E. Wolkenberg. "Total synthesis of Amaryllidaceae alkaloids utilizing sequential intramolecular heterocyclic azadiene Diels- Alder reactions of an unsymmetrical 1, 2, 4, 5-tetrazine." The Journal of organic chemistry 65, no. 26 (2000): 9120-9124.

15. Subas M. Sakya, Kelley K. Groskopf, and Dale L. Boger. "Preparation and inverse electron demand Diels-Alder reactions of 3-methoxy-6-methylthio-1, 2, 4, 5-tetrazine."
Tetrahedron letters 38, no. 22 (1997): $3805-$ 3808 .

16. Jianfu Ding, Naiheng Song, and Zhao Li. "Synthesis, characterization and photovoltaic applications of a low band gap polymer based on s-tetrazine and dithienosilole." Chemical Communications 46, no. 45 (2010): 86688670 .

17. Xiaowu Yu, Yanhua Luo, Wenxuan Wu, Qing Yan, Gang Zou, and Qijin Zhang. "Synthesis and reversible thermochromism of azobenzene-containing polydiacetylenes." European Polymer Journal 44, no. 9 (2008): 3015-3021.

18. Roxana Judele, Sabine Laschat, Angelika Baro, and Manfred Nimtz. "Gallic esters of 4, 5-dinitrocatechol as potential building blocks for thermotropic liquid crystals." Tetrahedron 62, no. 41 (2006): 9681-9687.

19. Jaroslaw Spychala, "4-(cyclic amidino) phenols-Preparation and use in a diamidine synthesis." Synthetic Communications 30, no. 6 (2000): 1083-109.

(Receievd 4/9/2018; accepted 26/9/2018)

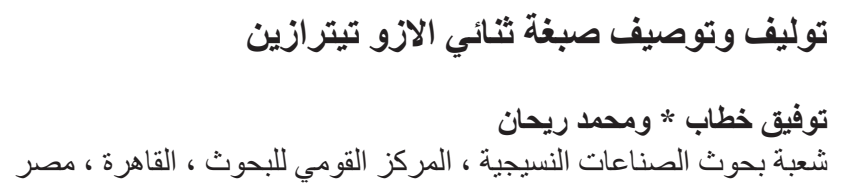

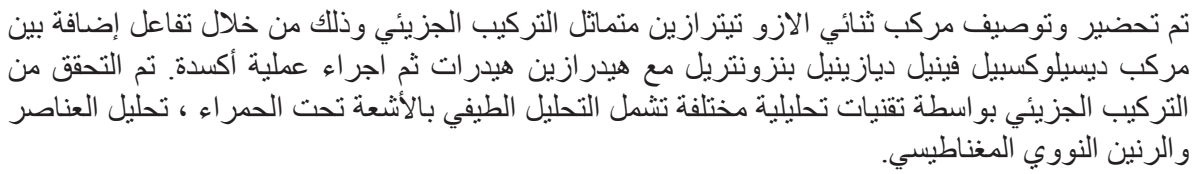

